\title{
Multisystemic Treatment of Antisocial Adolescents in Norway: Replication of Clinical Outcomes Outside of the US
}

\author{
Terje Ogden ${ }^{1} \&$ Colleen A. Halliday-Boykins ${ }^{2}$ \\ ${ }^{1}$ The Norwegian Center for Studies on Conduct Problems and Innovative Practice, PO Box 1039, Blindern, 0317 Oslo, \\ Norway. E-mail: terjeo@psykologi.uio.no \\ ${ }^{2}$ Family Services Research Center, Department of Psychiatry and Behavioral Sciences, Medical University of South \\ Carolina, 67 President Street - Suite CPP, PO Box 250861, Charleston, SC 29425, USA. E-mail: hallidca@musc.edu
}

\begin{abstract}
Background: MST is an intensive home- and community-based intervention for youths with serious antisocial behaviour and other serious clinical problems, which has been effective at reducing out-of-home placements and producing favourable long-term clinical outcomes in the US. The aims of the study were to determine the degree to which these outcomes would be replicated in Norway for youths with serious behaviour problems and to conduct a randomised trial of MST by an independent team of investigators. Method: Participants were 100 seriously antisocial youths in Norway who were randomly assigned to Multisystemic Therapy (MST) or usual Child Welfare Services (CS) treatment conditions. Data were gathered from youths, parents, and teachers pre- and post-treatment. Results: MST was more effective than CS at reducing youth internalising and externalising behaviours and out-of-home placements, as well as increasing youth social competence and family satisfaction with treatment. Discussion: This is the first study of MST outside of the US and one of the first not conducted by the developers of MST. The findings replicate those obtained by MST's developers and demonstrate the generalisability of short-term MST effects beyond the US.
\end{abstract}

Keywords: Antisocial behaviour; multisystemic therapy; treatment; young offenders

\section{Introduction}

Serious behaviour problems among children and adolescents are of great concern in Norway, as in other countries. Norwegian studies have indicated that behaviour problems occur in about $10 \%$ of youth, with the prevalence of serious problems in the range of 1-2\% (Ogden, 2002; Wichstroem, Skogen, \& Oia, 1996). Interventions to address these problems, however, have been inadequate (Kjellsberg \& Dahl, 1998; Norwegian Research Council, 1998). Consequently, the Ministry of Child and Family Affairs funded a project at the University of Oslo aimed at implementing and evaluating empirically-based interventions to reduce problem behaviour and to promote social competence among the most troubled youths. Two programs were selected because of their strong theoretical foundation and empirical support from controlled clinical outcome studies in the USA: Parent Management Training (Reid, Patterson, \& Snyder, 2002)was implemented for children aged 6 to 12 years (Ogden et al., 2003) and Multisystemic Treatment (MST; Henggeler et al., 1998) was implemented for adolescents aged 12 to 18 years. Starting in 1999, the process of implementing MST nation-wide has resulted in 25 MST teams covering 17 of the 19 county municipalities of Norway. The current study examines posttreatment outcomes for MST in four of the county municipalities.

MST is an intensive home- and community-based intervention for adolescents with serious antisocial behaviour and other serious clinical problems that has been effective at reducing out-of-home placements and producing favourable long-term clinical outcomes (see Halliday-Boykins \& Henggeler, 2001, for review). As detailed in clinical volumes (Henggeler et al., 1998, 2002) and substantiated by empirical evidence (Huey et al., 2000), MST decreases youth problem behaviour by improving family functioning and working directly with families in their social ecological context. In three randomised clinical trials (Borduin et al., 1995; Henggeler et al., 1997; Henggeler, Melton, \& Smith, 1992) involving more than 400 chronic and violent juvenile offenders and their families, MST has produced $25 \%$ to $70 \%$ decreases in long-term rates of re-arrest and $47 \%$ to $64 \%$ decreases in days in out-of-home placements, as well as significant improvements in both family and mental health functioning. Based on these findings, leading reviewers (e.g., Elliott, 1998; Kazdin, 1997; Farrington \& Welsh, 1999; Tate et al., 1995) and US policy makers (US Department of Health and Human Services, 2001) have concluded that MST is effective at decreasing adolescent criminal behaviour. Accordingly, MST has been widely disseminated for treating antisocial youth, being implemented in 30 states across the US and in 8 countries. The Norwegian MST project is breaking new ground, representing the first time MST is implemented in a non-English speaking country, as well as the first time that MST is implemented nation-wide, with one-third of all youths who receive in-home care through Child Welfare 
receiving MST (Statistics Norway, 2002). The generalisability of MST favourable outcomes to Norwegian youths, however, is not known. The aforementioned favourable clinical outcomes occurred during clinical trials conducted by the developers of MST with American youths.

The goals of the current study were two-fold. The first aim was to determine the degree to which favourable outcomes obtained in the US would be replicated in Norway for adolescents with serious behaviour problems. Key differences between the US and Norway in the social and political climate pertaining to the care of adolescents highlight the relevance of this research aim. In the US, for example, youths who commit criminal acts are typically handled by juvenile justice authorities, who provide dispositions designed to punish the offender and keep the community safe. In Norway, on the other hand, measures for offenders under the age of 15 years cannot be punitive or designed to protect the community, but rather, must be made in the best interest of the child (Ogden, 2000). No one under 15 years of age can be arrested, remanded in custody or sentenced to imprisonment, and offenders under the age of 18 years are seldom sent to prison, usually being handled by Child Welfare Services. Moreover, social services, healthcare and education are more comprehensive and more universally accessible in Norway than in the US. Accordingly, this study has implications for the extent to which MST can produce outcomes that are superior to the comprehensive and treatment-oriented services already provided to youth offenders in Norway, and more broadly, the degree to which US favourable outcomes are generalisable elsewhere.

The second aim of the study was to conduct a randomised trial of MST by an independent team of investigators. A treatment's degree of efficacy is bolstered by studies conducted by more than one research team (Chambless \& Hollon, 1998; Lonigan, Elbert, \& Johnson, 1998). The developers were not involved with the current study, making this one of the first trials of MST conducted by independent researchers. In addition, neither author participated in the training and supervision of MST therapists nor in the actual treatment of families. The paper examines posttreatment outcomes on youth symptomatology, family functioning, out-of-home placement, and satisfaction with treatment.

\section{Method}

\section{Participants}

One hundred adolescents and their families referred to treatment for serious antisocial behaviour participated in this study. The first four county municipalities to implement MST in Norway were invited to participate. For reasons not related to the MST program, the therapists at one site resigned. This site was replaced by one selected from the next group of teams to be trained. Each site contributed 25 cases to the study.

Inclusion criteria were: (1) problem behaviour such as law-breaking or other antisocial acts (e.g. aggressive and violent behaviour, serious rule breaking at home and/or at school, numerous and early sexual relations, for girls), serious academic difficulties, dysfunctional interpersonal relationships, verbal aggression and threats of hurting others; (2) age between 12 and 17 years; (3) parents (or parent surrogates) were sufficiently involved and motivated to start MST. Exclusion criteria were: (1) ongoing treatment by another agency; (2) substance abuse without other antisocial behaviour (although adolescents with substance abuse in combination with other antisocial behaviours were not excluded); (3) sexual offending; (4) autism, acute psychosis, or imminent risk of suicide; (5) presence of the youth in the home posed a serious risk to the youth or to the family; (6) ongoing investigation by the municipal child protective services. No youth referred was excluded according to these criteria.

The sample consisted of 63 boys and 37 girls, who averaged 14.95 years of age $(S D=1.87)$. Youths were referred for services for a range of behavioural and mental health problems, $44 \%$ of whom were referred for three or more reasons. Referral reasons included emotional disturbance (64\%), status offences (53\%), substance abuse (50\%), criminal offences $(37 \%)$, harm to self or other $(36 \%)$, involvement as victim or perpetrator in domestic violence (29\%), school expulsions $(6 \%)$, after care from a residential treatment centre or incarceration $(6 \%)$, abuse or neglect $(4 \%)$ or other reasons $(28 \%)$.

Almost all of the caregivers (95\%) had a Norwegian background. At the time of referral, most of the adolescents lived at home, with both of their parents (25\%), with their mother only (29\%), with their mother and another adult $(21 \%)$, or with their father $(9 \%)$. Other adolescents lived in hospitals or other institutions (9\%) or foster homes (6\%). As evidence of the youths ' need for intensive services, 39\% had been previously placed out of the home, $54 \%$ had a history of running away from home, 30\% had been suspended from school and $90 \%$ had a history of school truancy.

\section{Recruitment and randomisation}

All referrals to the study were made by the Municipal Child Welfare Services. All adolescents who display serious behaviour problems, including those under 15 years of age and most of those between the ages of 15 and 18 who break the law, are referred to Municipal Child Welfare Services. Such referrals can be made by police, school personnel or family members. If out-ofhome placement is recommended, municipal authorities refer youths to their county-level counterparts for specialised services. Specialised services have historically referred to out-of-home placements, but now also include MST. Treatment decisions for county-level specialised services are made by a team of professionals. All youths referred to county specialised services who met study inclusion criteria were invited to participate in the study. All families approached agreed to participate.

The families were randomly assigned to treatment conditions, with each having a $6 / 10$ chance of receiving MST and a 4/10 chance of receiving usual Child Welfare Services (CS). This weighted randomisation procedure was utilised because it was assumed that some of the MST families would prematurely drop out from treatment or withdraw from the outcome study, as MST was so divergent from usual care. This resulted in 62 families being assigned to MST and 38 families to CS. 


\section{Design and procedures}

A 2 (treatment type: MST vs. CS) x 2 (time: pretreatment, posttreatment) x 4 (county municipality) mixed factorial design was used with random assignment to treatment conditions. Assessments were conducted at study entry (prior to randomisation) and after termination of MST treatment (approximately 6 months after intake) or approximately 6 months after intake for the CS group. The participating families were given small economic compensation for completing each assessment.

\section{Measures}

Archival data pertaining to arrests and convictions are often considered ideal in the study of treatment of juvenile offenders. Norway's criminal justice system, however, does not make arrests and convictions for youths under 15 years, and offenders under the age of 18 are often handed over to the Child Welfare Services rather than prosecuted. Accordingly, archival data were not the most appropriate outcome measures for these adolescents. Instead, behaviours for the main outcomes were assessed using multiple informants (parents, teachers, youths). Parents and teachers are important persons with whom the adolescents interact on a daily basis, and although their ratings may be somewhat biased (Patterson, Dishion, \& Chamberlain, 1993), their assessments predict future offending and social impairment rather well (Kazdin, 1997). Measures were selected to assess key behavioural, mental health and placement outcomes, as well as the family relationships assumed to drive such outcomes. In addition, family satisfaction with treatment was assessed. The measures were selected among internationally standardised instruments, some of which had been translated into Norwegian and validated in previous studies (e.g. CBCL and SSRS), and others of which were translated and checked for internal consistency and face validity in the present study.

Child Behaviour Checklist (CBCL). Youth symptomatology was assessed by caregiver, adolescent and teacher ratings on the CBCL (Achenbach, 1991a) and associated measures (Youth Self-Report, Achenbach, 1991b; Teacher's Report Form, Achenbach, 1991c). This family of measures is one of the best validated for assessing child behavioural functioning. The CBCL consists of 20 social competence and 113 behaviour problem items applicable to children aged 4 to 18 years. It includes three broad band behaviour problem scales (Internalising, Externalising, and Total Behaviour Problems) and a broad band Social Competence score. This instrument has been translated into Norwegian and has demonstrated acceptable validity in Norway (Noevik, 1999). In the present study, the internal consistency was high for both internalising and externalising behaviours for all respondents ( $\alpha$ 's range from .81 to .94). Because $t$-scores based on US norms are not applicable to Norwegian youths, raw scores were utilised.

Self-Report Delinquency Scale (SRD). The 47-item SRD (Elliott, et al., 1983) is the best validated self-report delinquency scale (Henggeler, 1989). The SRD taps covert and overt antisocial behaviour that pertain to violent offending, general delinquency, and status offences. Internal consistency was very high (.95) in the present sample.

$C B C L$. Social Competence is assessed from adolescent, caregiver and teacher reports on the CBCL (Achenbach, $1991 \mathrm{a}, \mathrm{b}, \mathrm{c})$.

Social Competence with Peers Questionnaire (SCPQ). Youth social competence was measured with caregiver, adolescent, and teacher ratings on the SCPQ (Spence, 1995). This instrument is designed to assess the consequences of social interactions with peers. The youth version has 10 items, while the parent and teacher versions have 9 items. The SCPQ has demonstrated acceptable reliability across respondents ( $\alpha$ 's range from .83 to .93).

Social Skills Ratings System (SSRS). Because the SCPQ exclusively targeted peer relations, a scale was adapted from the SSRS (Gresham \& Elliott, 1990) to assess a broader array of social skills. The SSRS is a standardised, norm-referenced scale that assesses social skills, problem behaviours and academic competence of students from age 3 to 18 years. Ten items were selected from teacher, parent and student versions to assess cooperation, assertion, responsibility and self-control domains of social skills. The pronoun referent and item wording were modified to assess youth ratings. In addition, based on pilot studies with the complete instrument in Norway (Ogden, 2003), the response scale was modified from 3 to 4 points. This measure had a moderate level of internal consistency in the current sample $(\alpha=.64)$.

Family Adaptability and Cohesion Evaluation Scales-III (FACES-III). The FACES-III (Olson, Portner, \& Lavee, 1985 ) is a 20 -item self-report instrument that measures two key family constructs: cohesion (i.e. warmth) and adaptability (i.e. structure). Several studies have supported the sensitivity of the FACES subscales to MST treatment effects (e.g. Borduin et al., 1995; Henggeler et al., 1992, 1999). FACES-III was completed by both caregivers and adolescents. For parent and youth reports, respectively, internal consistency was high for cohesion (.83 and .86) and moderate for adaptability (.50 and .65).

Out-of-Home Placement. The youth's placement was measured using two parent-reported items that asked where the youth was living (1) at the time of the assessment and (2) most of the previous 6 months. Response options included various single- and two-parent home combinations (e.g. both parents, mother and other partner, father only), as well as out-of-home placements (e.g. foster parents, crisis/assessment institution, hospital). For each item, responses were dichotomised to indicate home vs. out-of-home placement.

Family Satisfaction Survey. Caregivers completed the Family Satisfaction Survey (Lubrecht, 1992) to indicate their extent of satisfaction with the services they received. This 12-item instrument assesses the caregiver's perception of treatment effectiveness, their willingness to utilise the services again or recommend 
them to others, as well as the quality of their interactions with the treatment personnel. Reliability was high $(=.83)$.

\section{Interventions}

Multisystemic Therapy. MST for youths with serious antisocial behaviour was implemented as detailed in the treatment manual (Henggeler et al., 1998) with no major modifications to the original intervention model. MST treatment was delivered by six MST teams. Each clinical team had three therapists and a clinical supervisor, and worked exclusively with MST. The MST therapists had a professional education equivalent to a masters or bachelors degree in social work, psychology or education and some of them also have additional training in family therapy. Three of the four MST clinical supervisors were licensed psychologists, while the fourth had a degree in social work.

Each therapist had a low caseload of 3-6 families and the teams were available to the families 24 hours a day, 7 days a week. The referrals to the research project started almost immediately after the teams had completed their introductory training week and 3-5 pilot cases.

MST is based on the social ecological perspective (Bronfenbrenner, 1979), asserting that behavioural changes in the youths are most robust when they occur by reorganising social environments rather than through individual, group or residential treatment. Accordingly, MST addresses systemic (e.g. family, peer, school) factors that contribute to problematic behaviour in addition to individual ones. Because these factors are differentially relevant across youth, MST interventions are flexible and individualised to meet the specific needs of each family. Interventions are held in the families' homes and communities (e.g. school) to reduce barriers to service access and to promote treatment generalisation. The interventions are focused on achieving the treatment goals by trying to mobilise family and community resources. They target specific, well-defined problems, focus on present conditions, and are action-oriented. Although the teams are accountable for the treatment outcome, daily or weekly efforts are expected from the family members in order to reach the goals and overcome obstacles.

Consultants from MST Services, LLC in Charleston, South Carolina (a university-affiliated training organisation) were responsible for the introductory training of the teams, and provided the teams with weekly telephone consultations and quarterly booster sessions. MST Services also participated in the site assessment before MST teams were established in order to ensure that goals and guidelines were consistent with the demand specifications in the MST Organisational Manual (Strother, Swenson, \& Schoenwald, 1998). Clinical supervision was offered on a weekly basis by the local MST supervisors.

In 1999 the health directors from all 19 of the Norwegian county municipalities were invited to participate in the national implementation of MST, and 16 accepted. The Ministry of Child and Family Affairs would pay for the training and consultation of the teams, while the county municipal Child Welfare Services hired the teams on a permanent basis.

The ministry also sponsored a national implementation and research unit at the University of Oslo,
Department of Psychology, with the first author as overall project director. The aims of the unit were to support and evaluate the quality of implementation and treatment effectiveness of MST and Parent Management Training Oregon (PMTO) model (Reid, Patterson, \& Snyder, 2002). Five years later (2003) the unit was transformed into 'The Norwegian Center for Studies of Conduct Problems and Innovative Practice' owned by the University of Oslo (UNIRAND) and sponsored by the Ministries of Child and Family Affairs, Health and Social Affairs, Education and Research, and Justice. This signalled a long term commitment from the involved ministries to support the implementation and further development of evidence-based interventions through a national rather than a regional or local centre. Two psychologists became program managers for the nationwide implementation of MST and PMTO. They have gradually built at team of 6 MST and 4 PMTO national consultants who are now doing most of the introductory and maintenance training, consultation as well as monitoring productivity and fidelity to the programs. The centre also have a research group of four (Ogden et al., 2003).

Usual Child Welfare Services (CS). Services are coordinated by both Municipal and County Municipal Child Welfare Services, who have a broad range of options. As previously discussed, out-of-home placements are considered 'specialised' services and handled by the County Municipal Child Welfare Services. Placement options include foster care and institutional placement. If the county-level authorities deem that out-of-home placement is not warranted based on the seriousness of the case, the case can be referred back to the municipal authorities, who provide less intensive services. Such services include home-based treatment or social work, including individual child counselling, parent training and promoting involvement in pro-social activities. In the present study, 14 youths received long-term institutional placement, 5 were placed in a crisis institution for assessment and in-home follow-up, 6 were supervised by a social worker in their homes, 7 were given other home-based treatment, and 6 refused the services offered.

\section{Attrition}

Early in treatment, four families withdrew from MST treatment ( $7 \%$ dropout). These families, however, were replaced with new ones. In addition, four families withdrew from the study prior to the posttreatment assessment, (3 CS, $1 \mathrm{MST}$ ), producing a research retention rate of $96 \%$. Because the government-approved informed consent allowed dropouts to have their data expunged from research records, no analyses could be conducted on treatment or research dropouts.

\section{Data reduction}

To produce the most reliable indicators of each construct and decrease Type 1 error, composite variables were created for each domain of youth and family functioning. Composites were created for internalising problems (caregiver, youth and teacher report on $\mathrm{CBCL}$ ), externalising behaviour (caregiver, youth and teacher report on the CBCL, youth report on SRD) and social competence (caregiver, youth and teacher report 
on CBCL, as well as youth report on the SCPQ and SSRS) based on the sum of standardised variables in each domain. In addition, the mean of raw scores of caregiver and youth reports on each family measure was employed.

\section{Results}

\section{Baseline comparisons}

At baseline, CS caregivers were more likely than MST caregivers to be divorced, and MST caregivers were more likely than their CS counterparts to be married to someone other than the child's biological parent $\left(\Pi^{2}\right.$ $(5)=14.2, p=.01)$. This difference had no moderating effect on the outcomes. No other significant baseline difference emerged between treatment conditions on demographic or psychosocial variables.

\section{Treatment outcomes}

ANOVA and chi-square results, including group means and standard deviations, are presented in Table 1. In these analyses, site (i.e. county municipality) was included as an independent variable to control for site effects. As treatment effects are the focus of this study, site effects are presented only secondarily.

Youth symptomatology. Based on combined caregiver, youth and teacher reports, youths in the MST condition demonstrated a significantly greater decrease in internalising behaviour $\left(\mathrm{F}_{1,86}=4.67, \mathrm{p}=.03\right)$ and a marginally significantly greater decrease in externalising behaviour $\left(\mathrm{F}_{1,88}=3.34, \mathrm{p}=.07\right)$ posttreatment than did their CS counterparts. The magnitude of treatment effects differed significantly across sites for both internalising $\left(\mathrm{F}_{3,86}=3.15, \quad \mathrm{p}=.03\right)$ and externalising $\left(\mathrm{F}_{3,88}=7.13, \mathrm{p}<.001\right)$ behaviour.

Youth Social Competence. Similarly, MST youths demonstrated a significant increase in social competence compared to CS youths $\left(\mathrm{F}_{1,91}=3.87, \mathrm{p}=.05\right)$.

Family functioning. Across treatment conditions, family cohesion increased significantly over time $\left(\mathrm{F}_{1,87}=5.43\right.$, $p=.02$ ), while family adaptability evidenced no significant change. Treatment effects were not observed for either of these family relationship measures.

Out-of-Home Placement. MST youths were maintained in the home significantly more often than CS youths. Of those at home during the pretreatment assessment $(n=84), 90.6 \%$ of MST youths were also at home during the posttreatment assessment, compared to $58.1 \%$ of CS youths $\left(\Pi^{2}(1)=12.27, p<.001\right)$. Similarly, for those who, at pretreatment, had spent the majority of the previous 6 months at home $(n=86)$, significantly more MST youths $(92.9 \%)$ than their CS counterparts $(73.3 \%)$ spent the majority of the 6 months prior to the posttreatment assessment at home $\left(\Pi^{2}(1)=6.20\right.$, $p=.01)$.

Satisfaction with treatment. Caregivers in the MST condition reported marginally significantly greater satisfaction with treatment than did their CS counterparts $\left(\mathrm{F}_{1,79}=3.27, p=.07\right)$.

\section{Discussion}

The findings from this study support the effectiveness of MST relative to the services usually available for adolescents with serious behaviour problems in Norway. Consistent with previous studies of MST with antisocial adolescents conducted in the US by the developers of MST (Borduin et al., 1995; Henggeler et al., 1997, 1992), MST was associated with decreased internalising and externalising (marginal) symptomatology in youths as well as increased youth social competence. MST also produced decreases in out-of-home placement and marginally greater caregiver satisfaction with treatment relative to $\mathrm{CS}$.

The favourable results obtained in this study demonstrate that the effects of MST generalise beyond samples of American youth, supporting country-wide implementation in Norway. That MST is effective with youths from such a different culture is consistent with the tenet that MST is equally effective with youths and families of varying backgrounds due to the inherent

Table 1. ANOVA and $t$-test results

\begin{tabular}{|c|c|c|c|c|c|c|c|c|}
\hline \multirow[b]{2}{*}{ Variable } & \multicolumn{2}{|c|}{$\begin{array}{l}\text { Usual child welfare } \\
\text { services }\end{array}$} & \multicolumn{2}{|c|}{ MST } & \multicolumn{2}{|c|}{$\begin{array}{l}\text { Treatment } \\
\text { effect }\end{array}$} & \multicolumn{2}{|c|}{$\begin{array}{l}\text { Time } \\
\text { effect }\end{array}$} \\
\hline & $\begin{array}{c}\text { Time } 1 \\
\text { Mean (SD) }\end{array}$ & $\begin{array}{l}\text { Time } 2 \\
\text { Mean (SD) }\end{array}$ & $\begin{array}{l}\text { Time } 1 \\
\text { Mean (SD) }\end{array}$ & $\begin{array}{c}\text { Time } 2 \\
\text { Mean (SD) }\end{array}$ & $F$ & $p$ & $F$ & $p$ \\
\hline \multicolumn{9}{|c|}{ Measures of youth functioning (z-score composites) } \\
\hline Internalising behaviour & $-0.10(0.67)$ & $0.14(0.61)$ & $0.06(0.70)$ & $-0.06(0.85)$ & 4.67 & .03 & 0.46 & ns \\
\hline Externalising behaviour & $-0.04(0.57)$ & $0.14(0.78)$ & $0.02(0.75)$ & $-0.03(0.71)$ & 3.34 & .07 & 1.30 & $n s$ \\
\hline Social competence & $0.13(0.60)$ & $-0.03(0.64)$ & $-0.11(0.56)$ & $-0.04(0.61)$ & 3.87 & .05 & 0.47 & ns \\
\hline \multicolumn{9}{|c|}{ Measures of family functioning (raw score composites) } \\
\hline Adaptability & $27.04(4.83)$ & $27.43(4.80)$ & $26.36(4.22)$ & $25.96(3.95)$ & 0.68 & ns & 0.00 & ns \\
\hline Cohesion & $30.90(5.64)$ & $32.16(4.72)$ & $29.42(6.35)$ & $31.66(7.10)$ & 0.97 & ns & 5.43 & .02 \\
\hline Satisfaction with treatment (raw scores) & & $3.23(0.51)$ & & $3.43(0.44)$ & 3.27 & .07 & na & \\
\hline \multicolumn{9}{|l|}{ Out of home placement (raw scores) } \\
\hline \multicolumn{9}{|l|}{ Of those home at $\mathrm{T} 1 \%$ home at $\mathrm{T} 2$} \\
\hline At time of assessment & & $58.1 \%$ & & $90.6 \%$ & $12.72 *$ & $<.001$ & na & \\
\hline Previous 6 months & & $73.3 \%$ & & $92.9 \%$ & $6.20 *$ & .01 & na & \\
\hline
\end{tabular}

*chi-square test. 
flexibility of the model (Brondino et al., 1997). The MST clinical team is responsible for doing whatever it takes to engage the family in treatment and services are individualised to meet the specific needs of each family. Findings from the current study suggest that this treatment model's success is not unique to American populations. Moreover, as one of the first randomised clinical trials of MST not conducted by the developers of MST, the favourable results of this study suggest that MST could be considered a well-established intervention for youth antisocial behaviour (Lonigan et al., 1998).

As previously mentioned, the community services to which MST was compared in the current study involved much more comprehensive and treatment-oriented services than have typically been available to juvenile offenders in MST research. The more modest treatment effects obtained in the current study relative to other trials may be attributable to the nature of the usual services condition. For example, in the two effectiveness trials of MST with juvenile offenders (Henggeler et al., 1992, 1997), the usual services condition consisted of probation office visits with referral to social services when deemed necessary. In the current study, on the other hand, the usual services condition involved a broad array of social services and mental health treatment, including institutional placement and in-home services. That MST obtained relatively favourable outcomes when compared to such comprehensive, treatment-oriented services is encouraging, and suggests that MST's positive effects obtained on US samples cannot be attributed primarily to a dearth of services typically available in the community for antisocial youth.

Importantly, some evidence suggested that treatment outcomes differed across sites. Previous MST research has shown that outcomes are linked to treatment fidelity (Henggeler, et al., 1997; Huey et al., 2000). To address the possibility that certain sites may have been implementing MST more effectively than others, MST treatment fidelity was examined using the Therapist Adherence Measure (TAM; Henggeler \& Borduin, 1992). In the current study, the site with the poorest MST outcomes reported having been unable to collect adherence measures, making it impossible to evaluate its treatment integrity. TAM scores differed significantly across the three remaining sites, with the site with the lowest score having the least favourable outcomes and the one with the highest score demonstrating the best outcomes. Accordingly, differential MST treatment effects across sites may be due to variability in the quality of treatment implementation. These findings illustrate the importance of examining site effects in multi-site studies.

The encouraging findings from the current study must be interpreted in light of some limitations. First, although conventional back-translation methods were used for translating the CBCL family of instruments into Norwegian, these approaches were not used for other measures. Thus some measures may not be directly comparable to their English counterparts. Nevertheless, the measures' face validity and high reliabilities, in addition to the use of multiple informants on the same construct, suggest that the composite variables were reliably assessing the intended con- structs. Second, outcomes were only assessed immediately posttreatment for MST. Efforts are currently underway to collect follow-up data to determine the stability of the treatment effects.

\section{References}

Achenbach, T. M. (1991a). Manual for the Child Behavior Checklist and 1991 profile. Burlington: University of Vermont, Department of Psychiatry.

Achenbach, T. M. (1991b). Manual for the Youth SelfReport and 1991 profile. Burlington: University of Vermont, Department of Psychiatry.

Achenbach, T. M. (1991c). Manual for the Teacher's Report Form and 1991 profile. Burlington: University of Vermont, Department of Psychiatry.

Borduin, C. M., Mann, B. J., Cone, L. T., Henggeler, S. W., Fucci, B. R., Blaske, D. M., \& Williams, R. A. (1995). Multisystemic treatment of serious juvenile offenders: Longterm prevention of criminality and violence. Journal of Consulting and Clinical Psychology, 63, 569-578.

Brondino, M. J., Henggeler, S. W., Rowland, M. D., Pickrel, S. G., Cunningham, P. B.., \& Schoenwald, S. K. (1997). Multisystemic therapy and the ethnic minority client: Culturally responsive and clinically effective. In D. K. E. Wilson, \& James R. Rodrigue (Eds.), Health-promoting and health-compromising behaviors among minority adolescents. Application and practice in health psychology (pp. 229-250). Washington, DC: American Psychological Association.

Bronfenbrenner, U. (1979). The ecology of human development. Cambridge, MA: Harvard University Press.

Chambless, D. L., \& Hollon, S. D. (1998). Defining empirically supported therapies. Journal of Consulting and Clinical Psychology, 66, 7-18.

Elliott, D. S. (1998). Blueprints for violence prevention. Boulder, CO: University of Colorado, Center for the Study and Prevention of Violence. Blueprints Publications.

Elliott, D. S., Ageton, S. S., Huizinga, D., Knowles, B. A., \& Canter, R. J. (1983). The prevalence and incidence of delinquent behavior: 1976-80. (Report of the National Youth Survey, Project Rept. \#26). Boulder, CO: Behavioral Research Institute.

Farrington, D. P., \& Welsh, B. C. (1999). Delinquency prevention using family-based interventions. Children and Society, 13, 287-303.

Gresham, F. M., \& Elliott, S. N. (1990). Social skills rating system. Circle Pines, MN: American Guidance Service.

Halliday-Boykins, C. A., \& Henggeler, S. W. (2001). Multisystemic therapy: Theory, research and practice. In E. Walton, P. A.Sandau-Beckler \& M. Mannes (Eds.), Balancing family-centered services and child-well being: Exploring issues in theory, practice, theory and research (pp. 320-335). New York: Columbia University Press.

Henggeler, S. W. (1989). Delinquency in adolescence. Newbury Park, CA: Sage.

Henggeler, S. W., \& Borduin, C. M. (1992). Multisystemic therapy adherence scales. Unpublished instrument. Department of Psychiatry and Behavioral Sciences, Medical University of South Carolina.

Henggeler, S. W., Melton, G. B., Brondino, M. J., Scherer, D. G., \& Hanley, J. H. (1997). Multisystemic therapy with violent and chronic juvenile offenders and their families: The role of treatment fidelity in successful dissemination. Journal of Consulting and Clinical Psychology, 65, 821833.

Henggeler, S. W., Melton, G. B., \& Smith, L. A. (1992). Family preservation using multisystemic therapy: An effective alternative to incarcerating serious juvenile offenders. Journal of Consulting and Clinical Psychology, 60, 953-961.

Henggeler, S. W., Rowland, M. D., Randall, J., Ward, D. M., Pickrel, S. G., Cunningham, P. B., Miller, S. L., Edwards, J., 
Zealberg, J. J., Hand, L. D., \& Santos, A. B. (1999). Homebased multisystemic therapy as an alternative to the hospitalization of youths in psychiatric crisis: Clinical outcomes. Journal of the American Academy of Child and Adolescent Psychiatry, 38, 1331-1339.

Henggeler, S. W., Schoenwald, S. K., Borduin, C. M., Rowland, M. D., \& Cunningham, P. B. (1998). Multisystemic treatment of antisocial behavior in children and adolescents. New York: The Guilford Press.

Henggeler, S. W., Schoenwald, S. K., Rowland, M. D., \& Cunningham, P. B. (2002). Serious emotional disturbance in children and adolescents: Multisystemic therapy. New York: The Guilford Press.

Huey, S. J., Jr., Henggeler, S. W., Brondino, M. J., \& Pickrel, S. G. (2000). Mechanisms of change in multisystemic therapy: Reducing delinquent behavior through therapist adherence and improved family and peer functioning. Journal of Consulting and Clinical Psychology, 68, 451467.

Kazdin, A. (1997). Practitioner review: Psychosocial treatment for conduct disorder in children. Journal of Child Psychology and Psychiatry \& Allied Disciplines, 38, 161-178.

Kjellsberg, E., \& Dahl, A. A. (1998). High delinquency, disability and mortality: A register study of former adolescent psychiatric in-patients. Acta Psychiatrica Scandinavia, 98, 34-40.

Lonigan, C. J., Elbert, J. C., \& Johnson, S. B. (1998). Empirically supported psychosocial interventions for children: An overview. Journal of Clinical Child Psychology, 27, 138-145.

Lubrecht, J. (1992). Family satisfaction survey. In K. Kutash \& T. R. Rivera (Eds.), Measures of satisfaction with child mental health services. Unpublished manuscript, Florida Mental Health Institute, University of South Florida.

Noevik, T. S. (1999). Validity and use of the Child Behaviour Checklist in Norwegian children and adolescents. An epidemiological and clinical study. Doctoral dissertation, Oslo, Centre for Child and Adolescent Psychiatry, Department Group of Psychiatry, University of Oslo.

Norwegian Research Council (1998). Barn og unge med alvorlige atferdsfuansker - hva kan nyere viten fortelle oss, hva slags hjelp trenger de (English: Children and youth with serious behaviour problems. What can be learned from contemporary research and what kind of help do they need?). A report from an expert group following the conference on 'Interventions for children and youth that are particularly aggressive and troublesome'). Oslo.
Ogden, T. (2000). The responses by the existing systems for dealing with juvenile delinquency in Norway. Committee of Experts on New Ways of Dealing with Juvenile Delinquency and the Role of Juvenile Justice.

Ogden, T. (2002). Children and adolescents' life conditions in the Nordic countries. Marginalisation of children and adolescents in the Nordic countries - An overview of current knowledge. Report, Copenhagen, Nordic Council of Ministers. Social Policy/Health.

Ogden, T. (2003). The validity of teacher ratings of adolescents' social skills. Scandinavian Journal of Educational Research, 47, 63-76.

Ogden, T., Forgatch, M., Askeland, E., Bullock, \& Patterson, G. (2003). Large scale dissemination and implementation of the PMTO model: The case of Norway. Manuscript submitted for publication.

Olson, D., Portner, J., \& Lavee, Y. (1985). FACES III. University of Minnesota, Department of Family Social Services.

Patterson, G. R., Dishion, T. J., \& Chamberlain, P. (1993). Outcomes and methodological issues relating to treatment of antisocial children. In T.R. Giles (Ed.) Handbook of effective psychotherapy. New York: Plenum Press.

Reid, J. B., Patterson, G. R., \& Snyder, J. J. (Eds.) (2002). Antisocial behavior in children and adolescents: A developmental analysis and a model for intervention. Washington DC: American Psychological Association.

Spence, S. H. (1995). Social skills training: Enhancing social competence with children and adolescents. Windsor, Berkshire, UK: NFER-NELSON Publishing Company.

Statistics Norway (2002). Children receiving assistance at home by the child welfare administrated by the counties, by type of assistance and county. Per 31 December 2001. Available: http://www.ssb.no/barnevernf_en/tab-2002-08-28-03-en. html.

Tate, D. C., Reppucci, N. D., \& Mulvey, E. P. (1995). Violent juvenile delinquents: Treatment effectiveness and implications for future action. American Psychologist, 50, 777-781.

Strother, K. B., Swenson, M. E., \& Schoenwald, S. K. (1998). Multisystemic therapy organizational manual. Charleston, MST-services.

US Department of Health and Human Services (2001). Youth violence: A report of the Surgeon General. Washington, DC: Author.

Wichstroem, L., Skogen, K., \& Oia, T. (1996). The increased rate of conduct problems in urban areas: What is the mechanism? Journal of American Academy of Child and Adolescent Psychiatry, 35, 471-479. 